\title{
Intravenous Nalbuphine as a Sole Analgesic in Head and Neck Oncosurgeries.
}

\author{
Ravindra Tandale ${ }^{1}$, Nayana Kulkarni', Sheetal Patil ${ }^{1}$, Rajnish Nagarkar ${ }^{1}$ \\ 'Department of Anesthesiology, HCG Manavata Cancer Centre, Nashik Fwy, Opp. Mahamarg Bus Stand, Renuka Nagar, Nashik- 422011, Maharashtra.
}

\section{Abstract}

Background: Aim: To assess the analgesic and hemodynamic stability of nalbuphine as a sole analgesic in head and neck oncosurgeris. Subjects and Methods: A prospective observational study was conducted to assess the effect of intravenous nalbuphine in adult patients undergoing head and neck oncology surgeries. A total of 101 ASA I to III patients were included in the study. Patients aged 18 to 80 years scheduled for head and neck oncology surgeries were included. Results: The average duration of analgesia was 223.63 minutes. The mean pulse rate preoperatively was $84.42 \pm 13.38$ per minute. The duration of analgesia ( 360 minutes) was highest in 38 patients while only two patients had an analgesic effect for 120 minutes. Only one patient reported to have respiratory depression while one had nausea. Post-operative ventilator was required for one patient. Conclusion: Nalbuphine can be considered as an ideal analgesic considering its efficiency in maintaining hemodynamic stability and effect of analgesia for long-duration surgeries. The side-effect profile of nalbuphine was favorable making it an ideal component for balanced anesthesia.

Keywords: Nalbuphine, balanced anesthesia, head and neck oncosurgery.

Corresponding Author: Dr. Ravindra Tandale, MD, Department of Anesthesiology, HCG Manavata Cancer Centre, Nashik Fwy, Opp. Mahamarg Bus Stand, Renuka Nagar, Nashik- 422011, Maharashtra.

Received: December 2018

Accepted: January 2019

\section{Introduction}

Anesthesiology has greatly evolved in the past 150 years as a major specialty as compared to other branches of medicine. There has been an increased understanding of monitoring, drug delivery, and physiology. Anesthesiology has made the most difficult diagnostic and surgical procedures easy to undertake, wherein earlier it was impossible. ${ }^{[1]}$ The concept of 'Balanced anesthesia was made known by John Lundy in 1926. A combination of technique and agents were required to provide effective analgesia. The use of appropriate premedication, regional anesthesia, and general anesthesia would help in producing different components of anesthesia. The triad of anesthesia comprises of analgesia, amnesia, muscle relation, and abolition of autonomic response while maintaining homeostasis. ${ }^{[2]}$ A plethora of anesthetic techniques are available for safe administration and early recovery of patients. Balanced anesthesia remains a big step towards achieving ideal anesthetic and high patient satisfaction. ${ }^{[3]}$

Intravenous analgesics were used for the first time during balance anesthesia in the US by Neffet in 1947. It was used by Mushin and Rendel Baker in 1949 in Great Britai. ${ }^{[4]}$ The use of agonist antagonist analgesic in intraoperative and postoperative settings has become an acceptable alternative. $^{[5]}$

Balanced anesthesia helps in maximizing patient comfort and safety while it minimizes patient risk. The purpose of balanced anesthesia include minimizing patient pain, clam the patient, and reduce the potential for adverse effects from anesthetic and/or analgesic agents. As per our experience, the surgical stress response reaches its peak during the postoperative period. It is known to have major effects on all body systems. Thus, it is necessary to have a pain and stressfree postoperative period as it helps in early mobilization and recovery. Minimizing postoperative pain is associated with reduction in overall morbidity and mortality. The ideal approach to prevent and control postoperative pain is to control it before it starts. The use of appropriate analgesics in the pre and intraoperative state may help in relieving pain, stress, discomfort, and adverse effects in the post-operative state. Some of the most common analgesic used include opioids such as morphine, fentanyl, butorphenol, buprenorphine, and nalbuphine; Nonsteroidal antiinflammatory drugs (NSAIDs) such as diclofenac, ketoprofe, caprofen, and meloxicam among others; local anesthetic agents such as bupivacaine, lidocaine, and ropivacaine; and $\mathrm{N}$-methyl-D-aspartate (NMDA) receptor antagonist such as ketamine. ${ }^{[5]}$ Nalbuphine Hydrochloride is an opioid agonist antagonist analgesic with reported cardiovascular stability, less nausea and vomiting, and lesser potential for respiratory depression. It is an ideal analgesic that can be used for balanced anesthesia. ${ }^{[6]}$

\section{Subjects and Methods}

A prospective observational study was conducted to 
determine the effect of intravenous nalbuphine in adult patients undergoing head and neck oncology surgeries. A total of 101 American Society of Anesthesiology (ASA) I to III patients were included in the study post-approval for the institutional ethical committees. Patients aged 18 to 80 years scheduled for head and neck oncology surgeries were included. Patients with ASA status IV and V were excluded from the study. Other exclusion criteria included patients with a history of alcohol or drug abuse, history of allergy to narcotics, chronic obstructive pulmonary disorder (COPD), psychological disorders, bronchial asthma, and ischemic heart disease (IHD). Informed consent from all study participants were taken after thorough pre-analgesic investigation. Patients were informed and educated about the visual analog score (VAS).

In the preoperative room, $20 \mathrm{G}$ cannula was inserted. In the operating room, all monitors, i.e. pulse oximeter, electrocardiogram, non-invasive blood pressure monitor, and capnography were installed and applied to all patients. Baseline parameters such as heart rate (HR), systolic blood pressure (SBP), diastolic blood pressure (DBP), and mean blood pressure (MBP), SpO2 and ECG were noted. All patients were pre-medicated with Glycopyrrolate $4 \mathrm{mcg} / \mathrm{kg}$, Inj. Ondansetron $0.08 \mathrm{mg} / \mathrm{kg}$, Inj. Midazolam $0.02 \mathrm{mg} / \mathrm{kg}$ and Inj. Nalbuphine $0.1 \mathrm{mg} / \mathrm{kg}$ intravenously. All patients were given general anesthesia after pre-oxygenation with $100 \%$ oxygen for three minutes.

In order to facilitate endotracheal intubation, intravenous propofol $2 \mathrm{mg} / \mathrm{kg}$ and intravenous suxamethonium $1.5 \mathrm{mg} / \mathrm{kg}$ was given. Post-endotracheal intubation, study participants were put on Intermittent Positive Pressure Ventilation (IPPV). A mixture of $\mathrm{N} 2 \mathrm{O}(50 \%)$ and $\mathrm{O} 2(50 \%)$ and isoflurane was used to maintain anesthesia. Intravenous atracurium was used as a muscle relaxant. As per patient requirement, intravenous normal saline (NS) and fluid ringer lactate were provided. Post-surgery patient was given intravenous Neostigmine $50 \mathrm{mcg} / \mathrm{kg}$ and Glycopyrrolate 8 $\mathrm{mcg} / \mathrm{kg}$ to reverse residual neuromuscular blockade. The patient was shifted to the intensive care unit on a T-piece.

The Ramsay sedation score and VAS were used to assess postoperative sedation in patients. The sedation and VAS scores were observed as different time intervals. In patients with a VAS of $\geq 4$ were given intravenous diclofenac 1.5 $\mathrm{mg} / \mathrm{kg}$ as rescue analgesic. Postoperative side effects such as vomiting, nausea, dizziness, respiratory depression, and headache were observed.

\section{Results}

A total of 101 patients were randomly selected for prospectively observation. The demographic and duration of surgery are shown in table 1 . The average duration of analgesia was 223.63. Minutes. The mean pulse rate preoperatively was $84.42 \pm 13.38$ per minute. There was a sudden increase in mean pulse rate $(89.25 \pm 10.75)$ immediately after induction [Figure 1]. However, the mean pulse decreased $(82.27 \pm 10.32)$ after five minutes of induction. The mean pulse was stable with minor fluctuations intra-operatively [Figure 1]. Post-induction, there was a sudden rise in blood pressure, SBP $142.42 \pm 19.91 \mathrm{mmHg}$; DBP $86.12 \pm 7.7 \mathrm{mmHg}$; and MBP $104.63 \pm 11.13 \mathrm{mmHg}$ (Fig.
2). There was a decline in blood pressure after five minutes of induction similar to those observed at baseline [Figure 2].

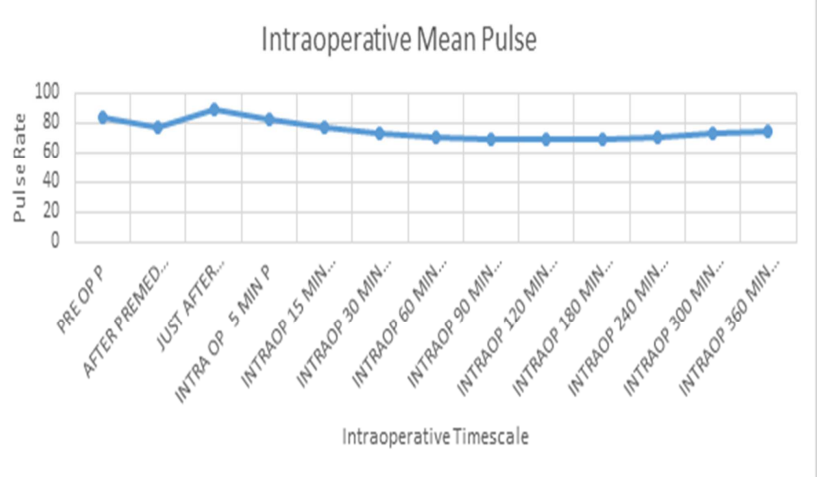

Figure 1: Intraoperative Mean Pulse

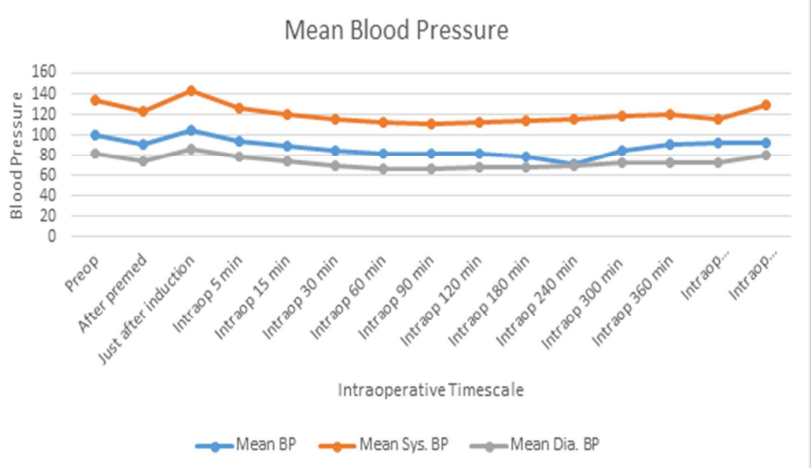

Figure 2: Intraoperative Mean Blood Pressure, Mean Systolic Blood Pressure, and Diastolic Blood Pressure

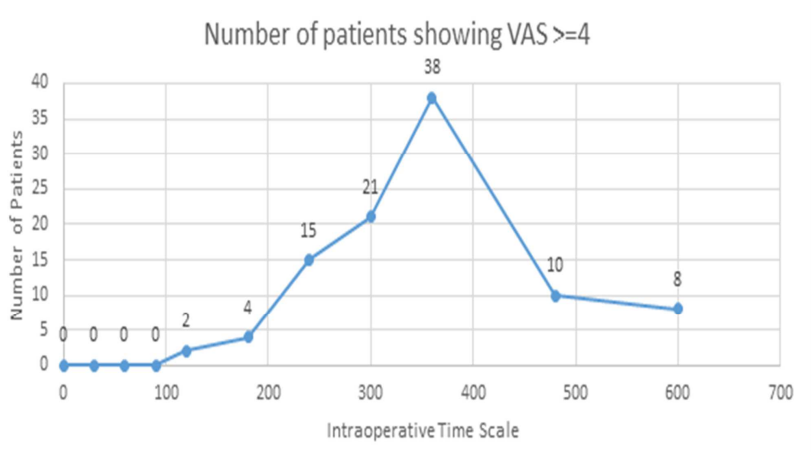

Figure 3: Number of patients showing VAS >=4

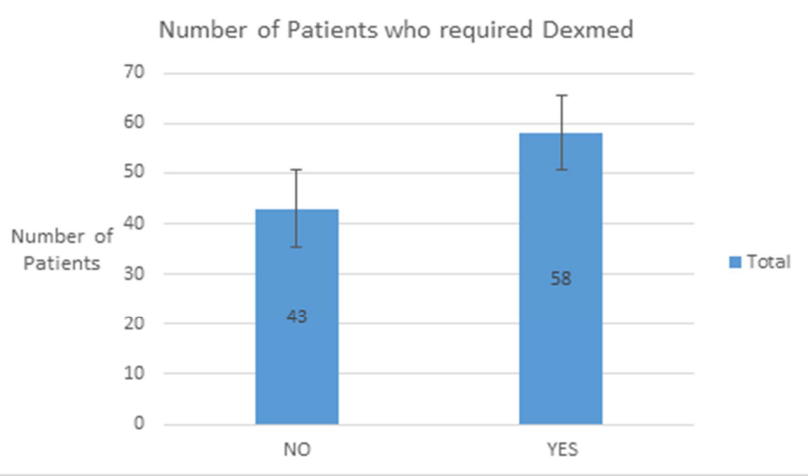

Figure 4: Number of patients who required Dexmed 
Table 1: Patient Demographics

\begin{tabular}{|l|l|}
\hline & Mean \pm SD (Standard Deviation) \\
\hline Age (years) & $48.79 \pm 10.60$ \\
\hline Sex (M:F) & $86: 15$ \\
\hline Weight (Kg) & $59.26 \pm 12.23$ \\
\hline ASA Status (I:II:III) & $6: 76: 19$ \\
\hline Duration of Surgery (min) & $184 \pm 172.82$ \\
\hline
\end{tabular}

Analgesic effect remains for 120 mins in 2 patients each. It was 180 mins in 4 patients, 240 mins in 15 patients and 300 mins in 21 patients. In 38 patients it was 360 mins. In 10 patients duration of analgesia was prolonged up to $480 \mathrm{mins}$ and in 98 patients it extends upto 600 mins as shown in [Figure 3].

In context to side-effects, only one patient had respiratory depression and one patient had nausea. Only one patient required postoperative ventilator. Patients were shifted or extubated on T-piece. None of the patients developed pruritus, hypoxia, or giddiness [Table 2].

As per our clinical practice, every patient undergoing head and neck onco-surgery was given intravenous tramadol, fentanyl, and dexmeditomidine. However, the use of intravenous nalbuphine eliminated the use of tramadol and fentanyl. It also reduced the use of dexmeditomidine by $42.5 \%$ for our study population [Figure 4]. None of the patients required fentanyl. The use of fentanyl is associated with unnecessary documentation and effort. None of the patients required Non-steroidal anti-inflammatory drug (NSAIDs).

Table 2: Patients with side effects postoperative

\begin{tabular}{|l|l|l|}
\hline & Side Effects & Number of Patients \\
\hline 1 & Nausea & 1 \\
\hline 2 & Vomiting & 0 \\
\hline 3 & Headache & 0 \\
\hline 4 & Giddiness & 0 \\
\hline 5 & Respiratory Distress & 1 \\
\hline
\end{tabular}

\section{Discussion}

Balanced anesthesia allows us to minimize patient risk and maximize patient comfort and safety. The objectives of the balanced anesthesia are to calm the patient, minimize pain, and reduce the potential for adverse effects associated with analgesic and anesthetic agents. Analgesics are used during balanced anesthesia for greater cardiovascular stability, reduction in dose requirement of muscle relaxant and volatile agent, rapid recovery of consciousness and minimal side effects during and after operation. Recovery of both consciousness and spontaneous ventilation is rapid. It reduces the operation theatre pollution due to volatile agent and possible adverse reaction to liquid agent.

In our study, we used nalbuphine, an opioid analgesic with a volatile anesthetic agent and muscle relaxant in order to achieve balanced anesthesia. The hemodynamic stability and analgesic efficacy was considered significant if the blood pressure and pulse rate changes were lesser than $20 \%$ of baseline value.

In our study, the rise in mean pulse rate and mean blood pressure intraoperatively was less than $20 \%$. This indicated hemodynamic stability intraoperatively using nalbuphine as a sole analgesic. The use of nalbuphine to prevent hemodynamic response was previously documented. ${ }^{[7-9]}$
The average duration of analgesia in our study was 223 minutes (approximately 3 and half hours). Intravenous diclofenac $1.5 \mathrm{mg} / \mathrm{kg}$ was given as rescue analgesic to our patients when the VAS score was $>4$.

Nalbuphine has been found to provide better pain relief and hemodynamic stability compared to tramadol in patients undergoing orthopedic surgeries. ${ }^{[10]}$ Nalbuphine was found to have a significant reduction in pain for the first two hours compared to fentanyl in patients who underwent short elective surgeries. When compared to fentanyl, nalbuphine was found to have a longer duration of postoperative analgesia with minimal side-effects. ${ }^{[1]}$

As per our experience, intraoperative arrhythmias and postoperative vomiting are common anesthesia-related complications of head and neck surgeries. These complications may be mediated by a range of vagal reflexes. Post-operative emesis is common complication among those given opioids for analgesia. As anesthetist, we aim for a rapid return of reflexes, pain-free, quiet, and non-emetic recovery from long duration head and neck surgeries. In the event when post-operative vomiting is undesirable, antiemetics are provided prophylactically with the induction of anesthesia.

\section{Conclusion}

Nalbuphine can be considered as an ideal analgesic in context to hemodynamic stability and intraoperative analgesia. Nalbuphine has minimal side-effects and can be considered as a component of balanced anesthesia.

\section{Acknowledgment}

We would like to thank Mr. Lyndon Fernandes for his medical writing assistance.

\section{References}

1. Agarwal A. The future of anaesthesiology. Indian Journal of Anaesthesia. 2012;56(6):524-528.

2. Bailey CR. New Balanced Anesthesia. Eur J Anaesthesiol. 2001. 18;5341

3. Tonner PH. Balanced anaesthesia today. Best Pract Res Clin Anaesthesiol. 2005;19(3):475-84.

4. Miller R. History of balanced anaesthesia. 330-331, 5th edition.

5. Badheka J, Parmar V, Chhaya VA, Patel N, Ramteke K and Mehta J: Study of Analgesic-Nalbuphine as a Component of Balanced Anaesthesia in Otolaryngorhinological Surgery. Int J Pharm Sci Res 2016; 7(12): 5012-16.doi: 10.13040/IJPSR.0975-8232.7(12).5012-16.

6. Chawda PM, Pareek MK, Mehta KD. Effect of Nalbuphine on Haemodynamic Response to Orotracheal Intubation. Journal of Anaesthesiology, Clinical Pharmacology. 2010;26(4):458-460.

7. Dabhi PG, Mehta $S$ et al, Effect of intravenous nalbuphine on hemodynamic response to laryngoscopy and intubation. Int $\mathbf{J}$ Res Med.:2104;3(4):24-27

8. Islam Md, Begum H, Akhhtaruzzaman AKM, and Khatun UH S. Study on efficacy of nalbuphine hydrochloride as pre emptive analgesic comparison with diclofenac sodium after open cholecystectomy. Journal of Bangladesh society of anaesthesiavol. 2007;20(2), 39-44.

9. Chawda PM, Pareek MK. Effect of Nalbuphine on Hemodynamic Response to Orotracheal Intubation. Journal of Anaesthesiology Clinical Pharmacology: 2010; 26(4):458-60.

10. Solanki R N, Gosai N D, Joshi GM, Patel BM, Modi HV, and Jain R. A Comparative Study of Intravenous NalbuphineHCl and Tramadol $\mathrm{HCl}$ for Post-Operative Pain Relief Following Orthopaedic Surgeries 
Asian Pac. J. Health Sci.,2015; 2(1): 155-60.

11. Panjabi G, and Tank P. A comparative study of nalbuphine and

fentanyl for post-operative pain relief in patient undergoing short surgical procedures. IOSR Journal of Dental and Medical Sciences: 2015;14(10):15-18

Copyright: ( ) the author(s), publisher. Academia Anesthesiologica International is an Official Publication of "Society for Health Care \& Research Development". It is an open-access article distributed under the terms of the Creative Commons Attribution Non-Commercial License, which permits unrestricted non-commercial use, distribution, and reproduction in any medium, provided the original work is properly cited.

How to cite this article: Tandale R, Kulkarni N, Patil S, Nagarkar R. Intravenous Nalbuphine as a Sole Analgesic in Head and Neck Oncosurgeries. Acad. Anesthesiol. Int. 2018;3(2):27-30.

DOI: dx.doi.org/10.21276/aan.2018.3.2.6

Source of Support: Nil, Conflict of Interest: None declared. 